\title{
Concurrent training in prepubertal children: An update
}

\author{
ANA R. ALVES ${ }^{1}$, CARLOS MARTA ${ }^{3,4}$, HENRIQUE P. NEIVA ${ }^{1,2}$, MIKEL IZQUIERDO $^{5}$, MARIO C. \\ MARQUES 1,2 \\ ${ }^{1}$ Department of Sport Sciences, University of Beira Interior, Covilhã, Portugal \\ ${ }^{2}$ Research Center in Sport Sciences, Health Sciences and Human Development, CIDESD, Portugal \\ ${ }^{3}$ Department of Sport Sciences, Guarda Polytechnique Institute, Guarda, Portugal \\ ${ }^{4}$ Research Unit for Inland Development, UDI, Guarda, Portugal \\ ${ }^{5}$ Department of Health Sciences, Public University of Navarre, Navarre, Spain
}

\begin{abstract}
This paper affords an update review over the state of art regarding the importance of physical fitness and the significance of different combination approaches between resistance and aerobic training, as well as conditioning methods exercise alone on physical fitness improvements, specifically explosive strength and cardiorespiratory fitness in prepubertal children. The main research conclusions can be summarized as: i) Resistance training can be reliable to improve muscle strength in prepubertal children; ii) A proper and quantifiable exercise frequency and intensity in aerobic training remains unclear; iii) No differences have been found between prepubertal girls and boys on strength and aerobic capacity improvements after intrasession concurrent training, resistance or aerobic training alone; iv) In adults, concurrent resistance and aerobic training seems to be more effective on improvements of aerobic capacity than aerobic training alone; v) Aerobic training biomechanically specific to the concurrent resistance training may minimize adaptation interference when concurrently training; vi) In adolescents, concurrent resistance and aerobic training is equally effective to improve explosive strength compared to resistance training alone, and more efficient in aerobic capacity than resistance training alone; vii) Optimum training sequence was determined by the individual purposes of the training program; viii) Performing aerobic prior to resistance training produces endurance gains, while performing resistance prior to aerobic training appears to be more adequate to obtain strength improvements; ix) In adults, performing concurrent training in different sessions seems to be more
\end{abstract}

Corresponding author. Department of Sports Sciences, University of Beira Interior, Rua Morais do Convento, 6201-001 (Covilhã) Portugal.

E-mail: mariomarques@mariomarques.com

Submitted for publication April 2017

Accepted for publication April 2017

Published in press May 2018

JOURNAL OF HUMAN SPORT \& EXERCISE ISSN 1988-5202

(c) Faculty of Education. University of Alicante

doi:10.14198/jhse.2018.133.18

682 | 2018 | ISSUE 3 | VOLUME 13

(c) 2018 University of Alicante 
effective to improve muscular strength than intra-session concurrent training. These results can be helpful for coaches, teachers and researchers to optimize explosive strength and cardiorespiratory fitness training in sports club and school-based programs, as well as a reliable source for further researches. Key words: PREPUBESCENT, PHYSICAL FITNESS, SEQUENCE, RESISTANCE, AEROBIC.

\section{Cite this article as:}

Alves, A., Marta, C., Neiva, H., Izquierdo, M., \& Marques, M. (2018). Concurrent training in prepubertal children: An update. Journal of Human Sport and Exercise, 13(3), 682-697. doi:https://doi.org/10.14198/ihse.2018.133.18 


\section{INTRODUCTION}

Physical fitness is considered a powerful health-related indicator in childhood (Ortega et al., 2008b) and an important element to the holistic child development (Marta et al., 2013; Ortega et al., 2008b). It is a complex and bidirectional concept that involves health-related and sport performance-related components (Caspersen et al., 1985, Garber et al., 2011). Even recognizing its importance for children by all community, a significant decrease in the practise of physical activity and consequently low physical fitness levels among children was found over the last decade (Matton et al., 2007; Moreno et al., 2007). This seemed to be the main cause of most of health issues during childhood, for instance cardiovascular disease (Steele et al., 2008; Tambalis et al., 2013). Thus, it is important to consider children and adolescents as the primary prevention of diseasesrelated to sedentary lifestyle (Martínez-Vizcaíno \& Sánchez-López, 2008). Concerning to the abovementioned, the efforts to increase physical fitness levels in youth should be a priority (Cepero et al., 2011).

Most of the paediatric research based on training programs focused on activities that enhance cardiorespiratory fitness, neglecting the neuromotor fitness conditions based on muscular strength (Cepero et al., 2011). Yet, improvements in muscular fitness, speed and agility, rather than cardiorespiratory fitness, seem to have a positive effect on skeletal health (Kemper et al., 2000; Santos et al., 2012). Therefore, recent investigations indicated that resistance training provide benefits to children and adolescents (Kemper et al., 2000; Santos et al., 2012), being considered a reliable and effective method of conditioning (Faigenbaum et al., 2009b). Nevertheless, another conditioning method, called concurrent training, has been investigated over the last decades. Actually, it was suggested to provide gains in cardiorespiratory and muscular fitness simultaneously (Kang \& Ratamess, 2014). To the best of our knowledge, little is known about the effects of concurrent training on prepubertal children performance (Greenleaf et al., 2010; Marta et al., 2013). Moreover, the effects of intra-session concurrent training order were only investigated in adults (Cadore et al., 2011; 2012; Chtara et al., 2005). Therefore, it seems to be important to investigate the effects of different approaches between resistance and aerobic training on explosive strength and cardiorespiratory fitness in prepubertal children. Furthermore, this investigation can be useful to coaches, teachers and researchers to optimize explosive strength and cardiorespiratory fitness training in sports club and school-based programs, as well as a reliable source for further researches.

\section{METHODS}

An updated review was produced over the state of art concerning the importance of physical fitness and the significance of different combination approaches between resistance and aerobic training, as well as conditioning methods exercise alone on improvements of physical fitness, specifically explosive strength and cardiorespiratory fitness in prepubertal children. To this purpose, a literature search was conducted in MedLine and SportsDiscus and the following combination of keywords was applied: physical fitness, concurrent training, prepubescent children, resistance training, aerobic traininig. Papers written in English and Brazilian were considered for this review.

\section{Physical Fitness in childhood}

Physical fitness has been considered an important health-related marker in childhood and a significant element for normal child growth and development (Marta et al., 2013; Ortega et al., 2008b). In fact, it is recognised a positive relation between the physical fitness development and health. The enhancement on physical fitness levels provide several benefits in children, as improvements on cardiorespiratory performance, cardiovascular health, muscular strength, total and abdominal adiposity, depression levels 
decreases, better anxiety control, self-esteem increases, and higher academic performance (Cepero et al., 2011).

Although there are reliable evidences about the several benefits associated to good physical fitness levels, some researchers indicated a decline on physical activity practise and decreases on physical fitness levels among children over the last few decades (Matton et al., 2007; Trost et al., 2002). This overview may be attributed to a perceptible refusal of children in physical education classes and regular physical activity (Roetert, 2004), but also to sedentary behavioral, physiological and psychological factors (Tomkinson \& Olds, 2007). So, it seems to be relevant to promote improvements of physical fitness levels in youth (Cepero et al., 2011), whereas favourable behavioural and biological effects during childhood may support to reduce the risk of developing chronic diseases into later life (Ortega et al., 2008a).

\section{Resistance training}

Youth resistance training is becoming universal as a qualified method of conditioning by medical, fitness, and sports organizations (Faigenbaum \& Westcott, 2009a; South African Sports Medicine Association, 2008). Early scientific researches evidence that resistance training can provide exclusive benefits for children and adolescents when properly designed and well-supervised (Faigenbaum et al., 2009b; Vaughn \& Micheli, 2008). Indeed, resistance training has innumerable health-related benefits such as decreases on cardiovascular disease (Ortega et al., 2012) and chronic disease risks as diabetes, obesity (Wijndaele et al., 2007), improvements on bone health (Pitukcheewanont et al., 2010), body composition (Sadres et al., 2001; Santos et al., 2014), phychosocial well-being (Yu et al., 2008), motor control skills (Hass et al., 2001), muscular and explosive strength in children and adolescents (Benson et al., 2007).

In the last three decades, resistance training was not recommended for children as it was believed to lead to injuries and long-term health consequences as damage of growth plates and premature closure of epiphyses, while at the same time thought to be ineffective in strength improvements (Faigenbaum et al., 1996). However, scientific researches highlighting positive results such as bone mineral density improvements, muscular and endurance improvements in prepubertal and pubertal subjects after a resistance training beyond normal growth and maturation (Benson et al., 2007; Steinberger, 2003). Furthermore, children can improve muscular strength after 8 to 12 weeks of a resistance training program with two training sessions per week (Dahab \& McCambridge, 2009). In early meta-analyses (Payne et al, 1997; Falk \& Tenenbaum, 1996) gains in muscle strength were suggested to be closely $13-30 \%$ greater than those which should be hoped from growth and maturation (Falk \& Tenenbaum, 1996).

The physiological mechanisms behind training-induced strength gains during preadolescence have been attributed mainly to neurological adaptations (i.e., increased motor unit activation, changes in motor unit coordination, recruitment) than hypertrofic factors (Malina, 2006; Ozmun et al., 1994; Ramsay et al., 1990), reporting differences with adults which attribute these improvements to hormonal and neural mechanisms (Faigenbaum et al., 2004; Ramsay et al., 1990). Concerning to the prepubertal gender differences, some researchers reported that there is no difference in strength between prepubertal girls and boys (Faigenbaum et al., 2003).

A reasoned compilation of scientific researches suggests that youth resistance training should be an important component of youth fitness programs, health promotion objectives, and injury prevention (Faigenbaum et al., 2009b). On this, Tsolakis et al. (2004) examined the influence of 8 -weeks progressive resistance training program ( 3 times per week, $3 \times 10$ repetitions maximum [RM]) on strength in prepubertal males ( $11.8 \pm 0.8$ years). The 2-months resistance training program resulted in $17.5 \%$ increase in isometric 
strength in experimental trained group compared with control group. Sadres et al. (2001) analyzed the effect of 2 school years (21months) of a twice-weekly resistance training program (1-4 set of 3-6 exercises, with 530 repetitions/set, load ranged $30-70 \% 1 \mathrm{RM})$ on muscle strength in prepubertal males $(9.2 \pm 0.3$ years). The results showed significantly increases in experimental group on muscle strength (knee extensors: $83 \%$ and knee flexors: 63\%). Curiously, these evidences were corroborated by Szymanski and colleagues (2007) which suggested that longer program duration, higher frequency and intensity have a greater influence on the magnitude of strength changes. Regarding injury prevention, early studies that included experimental protocols with resistance training demonstrated effectiveness to reduce sports related injuries in youth (Micheli et al., 2000; Abernethy \& Bleakley, 2007). Concerning to the health promotion purposes, Sung et al. (2002), analyzed the effects of resistance training (6 weeks, twice-weekly, circuit of 20 exercises repetitions, load ranged $75-100 \% 10 \mathrm{RM}$ ) in prepubertal children (8-11 years) on blood lipid profile. The authors observed improvements on fat free mass $(+2.3 \%, p<0.05)$ in experimental group after implemented program.

\section{Aerobic training}

Aerobic fitness reports to the body's capacity to transport oxygen from the environment and use it in muscle work. It is not only mentioned as a performance's determiner in a wide range of activities, but also a healthrelated mark since more than two decades ago when Blair et al. (1989) demonstrated that higher aerobic fitness measured during an additional treadmill exercise test was associated with reduced all-cause mortality in adults (Andersen \& Haraldsdóttir, 1994; Malina et al., 1995). In a health context, aerobic training has been associated with a lower risk of diabetes, coronary heart disease, and obesity in children (Ortega et al., 2007). Moreover, higher levels of cardiorespiratory fitness are associated with a healthier cardiovascular profile later in life (Ortega et al., 2007; Ruiz et al., 2009). In performance context, aerobic training aims to increase maximal oxygen uptake $\left(\mathrm{VO}_{2 \mathrm{max}}\right)$ or other physical fitness markers (i.e., lactate/ventilator threshold, exercise efficiency) (Baquet et al., 2003).

Child-based studies have widely focused on improving fitness levels for either athletic performance or for its relationship with health outcomes (Matos \& Winsley, 2007). However, training-induced adaptations in aerobic fitness have been a matter of long-lasting controversy in children. Several studies have concluded that aerobic training did not produced significant changes in VO2max before puberty (Kobayaski et al., 1978; Mirwald et al.,1981), being explained by the existence of a maturational threshold (Katch, 1983). However, others researchers have shown significant improvements in VO2max in the same age (Pfeiffer et al., 2008; Shephard, 1992). But, this controversy may be clarified by the differences in experimental design (Armstrong \& Welsman, 1990; Baquet et al., 2003).

Early reviews reported that the magnitude of training-induced changes in children might be smaller than that expected in adolescents and adults (Armstrong \& Welsman, 2002; Mahon, 2000; Pate \& Ward, 1990). As Armstrong \& Welsman (2002) mentioned "children are not mini-adults", and their responses appear to be differently on exercise stimulus comparing to the adults (Matos \& Winsley, 2007). Yet, a sufficient training stimulus must be provided for a significant enhancement of the VO2max in children (Carazo-Vargas \& Moncada-Jiménez, 2015) and the magnitude of the response will be influenced by exercise intensity and frequency (Baquet et al., 2003).

Regarding to the training frequency, some researches revealed that the gain in peak VO2 was improved in prepubertal children by doing exercise program at least two sessions per week. Baquet et al. (2002) observed the effects of a 7-week (twice per week) of high intensity aerobic intermittent training programme on peak VO2 of prepubertal children. The peak VO2 improved by $8.2 \%$ in experimental group, while no alterations were noticed for control group. Mandigout et al. (2001) showed a significant increase about 7.1\% in VO2max 
after implementing an aerobic training programme during 13 weeks (three sessions per week). In fact, these evidences are consistent with Baquet and colleagues (2003). These authors stated that, independently of sex or pubertal status, mean peak VO2 increase was around 5-6\%, or even 8-10\% when considered just studies that showed significant training effect.

There is a controversy concerning to the training intensity in children. It is reported that children need to train at a higher exercise intensity to elicit increases in aerobic fitness (Matos \& Winsley, 2007). Furthermore, Massicotte \& Macnab (1974) analyzed three different groups of prepubertal boys set distinct training intensities for each group. The results evidenced that only boys who performed at highest intensities (approximately $88 \%$ heart rate maximum) evidenced an increase about $11 \%$ in peak VO2. However, the results of Carazo-Vargas \& Moncada- Jiménez (2015) contrasts with previous evidences. The authors found that moderate exercise intensity (approximately 60\% of an individual's heart rate maximum) provided adequate stimulus for a VO2max improvement. Hereupon, the children's ability to improve their aerobic capacity by aerobic training is demonstrated. However, further experimental research is required to define a proper and quantifiable exercise frequency and intensity (Carazo-Vargas \& Moncada- Jiménez, 2015).

Regarding to the prepubertal gender differences', there was no difference in aerobic capacity improvements between boys and girls. Baquet and colleagues (2002) applied a 7-week aerobic training programme (twice a week) in prepubertal children and observed identical responses in aerobic performance, peak VO2 increase $9.5 \%$ in prepubertal boys and $7.2 \%$ in prepubertal girls.

\section{Concurrent resistance and aerobic training}

The compatibility of resistance and aerobic training performed simultaneously, called as concurrent training (Fyfe et al., 2014), has been investigated over the last three decades (Arazi et al., 2011; Davis et al., 2008a, 2008b).

Actually, concurrent training seems to be a potential strategy for preventing and stabilizing multiple disease states due to its capacity to induce adaptations within skeletal muscle that neutralize a number of disorders impacting upon functional capacity and metabolic health, including sarcopenia (Pijnappels et al., 2008), type II diabetes, and obesity (Kelley et al., 2002). However, concurrent training has become a recurrent topic for researchers due to the controversial results of different studies (Cadore et al., 2014; García-Pallarés \& Izquierdo, 2011). Hickson (1980) reported a compromised adaptation induced by concurrent training compared with training exercise mode alone (Leveritt et al., 1999), calling the phenomenon as 'interference effect' (Wilson etal., 2012). In fact, some studies reported that concurrent training may affect the development of muscle strength and/or power (García-Pallarés \& Izquierdo, 2011; Izquierdo et al., 2005; IzquierdoGabarren et al., 2010), while others contradicted by showing a positive effect of concurrent training on maximal aerobic capacity (McCarthy et al., 1995; Silva et al., 2012), muscular strength (Davis et al., 2008a; Davis et al., 2008b; Gravelle \& Blessing, 2000; Kraemer et al., 1995; Shaw et al., 2009), muscular endurance (Kraemer et al., 1995), and body composition (Rahnama et al. 2007). However, these studies have investigated concurrent training in young, adult and elderly populations (Chtara et al., 2005, Davis et al., 2008a, 2008b, Holviala et al., 2010; Takeshima et al., 2007). There are a limited number of studies that explored concurrent training in prepubescent children (Marta et al., 2013).

Some variables have been suggested to affect concurrent training beyond those that typically characterize a training program (i.e. frequency, intensity, volume) such as: training design [i.e. concurrent training performed simultaneously during the same session, in the same day (i.e. in the morning and in the evening) or in different days (i.e. resistance exercise on Monday, endurance exercise on Tuesday, and so on), or during specific 
training cycles] (Kang \& Ratamess, 2014), and intra-session training sequence (i.e. aerobic prior to resistance training, or resistance prior to aerobic training) (Chtara et al., 2005).

\section{Intra-session concurrent training}

The intra-session resistance and aerobic training has been reported to be usual in physical fitness training programs due to time constraints and convenience (Alves et al., 2012). However, this training design represents a specific challenge as the fatigue produced from one type of exercise may negatively influence the magnitude and quality of exercise in the other type reporting to possible interference effect (Davis et al. 2008a, 2008b). In fact, Cadore et al. (2010) reported increases about 50\% in knee extensor strength from resistance training alone group compared with concurrent training group. Gergley (2009) also found higher values in the resistance training alone group, but creatively presented significant improvements in concurrent training group where cycling was added to aerobic training compared with the group where resistance training was combined with running. This evidence supported that aerobic training biomechanically particular to the concurrent resistance training may minimize adaptation interference when concurrently training. The efficiency of intra-session concurrent training in aerobic capacity have been confirmed though the study of Chtara et al. (2005). This study presented even larger increases in maximal oxygen uptake in the concurrent training group where aerobic precedes resistance training when compared to aerobic training alone group. Additionally, Santos et al. $(2011,2012)$ compared the effects of an 8-weeks training period of resistance training alone $(\mathrm{R})$ and concurrent resistance and aerobic training (RA) on body composition, explosive strength and $\mathrm{VO}_{2 \max }$ adaptations in adolescent's girls and boys. It was found similar improvements on explosive strength in both experimental groups (girls: R 8.0\% and RA 12.0\%; boys: R $10.3 \%$ and RA 14.4\%), but improvements on $\mathrm{VO}_{2 \max }$ were only observed in intra-session concurrent resistance and aerobic training (girls: RA 4.0\%; boys: 4.6\%). In the same line of thinking, Marta and colleagues (2013) reported an equally effectiveness of concurrent training group on training-induced explosive strength (R: $5.3 \%$; RA: $5.2 \%$ ), and more efficient than resistance training alone in $\mathrm{VO}_{2 \max }(\mathrm{R}: 0.8 \%$; $\mathrm{RA}: 3.3 \%)$ in prepubertal children.

Order of intra-session concurrent training

Since resistance and aerobic training are performed concurrently, seems to be important to understand if there is an optimal training design or sequence for improving the physiological adaptations to exercise (Collins \& Snow, 1993). The intra-session exercise sequence might be an important variable in the concurrent training prescription (Chtara et al., 2005; García-Pallarés \& Izquierdo, 2011) and may define the magnitude of impairment in strength (Leveritt \& Abernethy, 1999) or aerobic capacity (Chtara et al., 2005) development after concurrent resistance and aerobic training.

Performing aerobic exercise prior seems to be reliable because it can serve as a sufficient warm-up of muscle prior to the start of resistance exercise (Kang et al., 2009). But this sequence may result in a peripheral fatigue that consequently reduces performance during the resistance training. In the other hand, performed resistance exercise prior to aerobic exercise express a greater increase in lipolysis during subsequent aerobic exercise, suggesting that this exercise sequence may be more beneficial metabolically (Kang et al., 2009). However, early researches focused on the concurrent training sequence effects on performance and health (Chtara et al., 2005; Kang \& Ratamess, 2014) concluded that optimum training sequence was determined by the individual purposes of the training program.

In practical issues, performing aerobic prior to resistance training produces aerobic gains, while performing resistance prior to aerobic training appears to be more adequate to obtain strength improvements (Kang \& Ratamess, 2014). Chtara et al. (2005) examined the effects of the concurrent sequencing order training during 12 weeks (twice per week) on aerobic performance and capacity of male students. It was reported 
greater improvements of $\mathrm{VO}_{2 \max }$ and aerobic performance in experimental group which perform aerobic prior to resistance exercise $(13.7 \% ; 8.6 \%$, respectively), compared to resistance prior to aerobic exercise $(11.0 \%$; $4.7 \%$, respectively) and aerobic training alone group (10.1\%; $5.7 \%$, respectively). Additionally, Cadore et al. (2011) have supportively shown similar magnitude improvements in maximal aerobic power in the concurrent training group where aerobic preceded resistance training $(10.0 \%, p<0.05)$ and in the aerobic-only group $(10.6 \%)$.

Separate day concurrent training

Concurrent training has been investigated by its potential to provide about gains in cardiorespiratory and muscular fitness simultaneously (Kang \& Ratamess, 2014). However, adaptations to exercise training, performance improvements and training outcomes are highly specific to the mode of activity performed (Küüsma, 2013).

Sale et al. (1990) reported that the design of separate day resistance and aerobic training may be more effective to improve muscular strength than resistance and aerobic training on the same day. Concordantly, Garcia-Pallarés \& Izquierdo (2011) found that, the strength gains were significantly higher in the group that performed the training sessions on different days. Furthermore, Häkkinen et al. (2003) showed that after an extended training period of 21-weeks both concurrent resistance and aerobic as well as resistance training alone group resulted in similar gains in maximal lower body strength, but it was not the case in rapid force production. In fact, those inversely affected gains in strength and power can be observed especially when high volumes, intensities, and/or frequencies are employed (Chtara et al., 2008; Hickson, 1980; Kraemer et al., 1995; Sale et al., 1990).

To acquire optimal adaptations in muscle strength and power, as well as to minimize interference phenomenon, training frequency should not be in excess. Concurrent training showed to be detrimental for strength gains only when frequency is more than 3 days per week (García-Pallarés \& Izquierdo 2011). In addition, interference in the improvement of physical fitness is usually observed only during a long (>7-8 weeks) training period (Hickson, 1980; Izquierdo et al., 2003). In studies where the training frequency have not exceeded 3 days per week, increases in maximum strength were detected following concurrent training periods between 8 and 16 weeks (Izquierdo-Gabarren et al., 2010; McCarthy et al., 2002) and $\geq 20$ weeks (García-Pallarés et al. 2010; Häkkinen et al., 2003). This is consistent with Sillanpää and colleagues (2008) that analyzed the effects of a 21-weeks (twice a week) of resistance and/or aerobic training on body composition and physical fitness of older man. The authors observed similar gains in maximal concentric force in the resistance training $(+22.0 \%)$ and concurrent training group $(+23.0 \%)$, as well an improvement in maximal oxygen uptake in aerobic training and concurrent training group (both with improvements by $11.0 \%)$, with no changes in control group (C).

\section{CONCLUSIONS}

The importance of physical fitness specially during childhood is consensual and in order to improve it, and consecutively several health related and sport performance parameters, different conditioning methods could be suggested, such as: resistance training, aerobic training or even concurrent resistance and aerobic training. Regarding the resistance training, scientific researches underlining its efficiency on improving bone density, muscular and endurance strength of children without compromising their normal growth. Concerning to the aerobic training, it has been proved its effectiveness on improvements of children aerobic capacity. Lastly, the intra-session concurrent training has been demonstrated as an effective method to improve explosive strength and $\mathrm{VO}_{2 \max }$ in children. However, further investigation is needed to know the effects of 
different approaches between resistance and aerobic training on explosive strength and cardiorespiratory trainability in prepubertal children.

The main findings of this review can be mentioned as:

i) Resistance training can be an effective and reliable to improve muscle strength in prepubertal children;

ii) A proper and quantifiable exercise frequency and intensity in aerobic training remains unclear;

iii) No differences have been found between prepubertal girls and boys on strength and in aerobic capacity improvements after intra-session concurrent training, resistance or aerobic training alone;

iv) In adults, concurrent resistance and aerobic training seems to be more effective on improvements of aerobic capacity than aerobic training alone;

v) Aerobic training biomechanically specific to the concurrent resistance training may minimize adaptation interference when concurrently training;

vi) In adolescents, concurrent training can be equally effective to improve explosive strength compared to resistance training alone, and more efficient in aerobic capacity than resistance training alone;

vii) Optimum training sequence was determined by the individual purposes of the training program;

viii) Performing aerobic prior to resistance training produces aerobic gains, while performing resistance prior to aerobic training appears to be more adequate to obtain strength improvements;

ix) In adults, performing concurrent training in different sessions seems to be more effective to improve muscular strength than intra-session concurrent training;

x) The effects of concurrent resistance and aerobic (intra-session and different sessions), as well its intra-session sequence in prepubertal children, has still to be investigated.

\section{FUTURE RESEARCHES}

After summarizing all research findings, researchers should suggest future investigation in order to explore unclear issues in the available literature. Some of those main issues could be pointed:

i) The effects of concurrent resistance and aerobic training on physical fitness in prepubertal children;

ii) The magnitude of differences between intra-session and separate-session on physical fitness;

iii) The magnitude of intra-session concurrent resistance and aerobic training order on physical fitness.

\section{REFERENCES}

Abernethy, L., \& Bleakley, C. (2007). Strategies to prevent injury in adolescent sport: A systematic review. British Journal of Sports Medicine ,41(10), 627-638. https://doi.org/10.1136/bjsm.2007.035691

Alves, J.V., Saavedra, F., Simão, R., Novaes, J., Rhea, M.R., Green, D., \& Reis, V.M. (2012). Does aerobic and strength exercise sequence in the same session affect the oxygen uptake during and 
post-exercise? Journal of Strength \& Conditioning Research, 26(7), 1872-1878. https://doi.org/10.1519/JSC.0b013e318238e852

Andersen, L.B., \& Haraldsdóttir, J. (1994). Changes in CHD risk factors with age: a comparison of Danish adolescents and adults. Medicine \& Science in Sports \& Exercise, 26(8), 967-72. https://doi.org/10.1249/00005768-199408000-00006

Arazi, H., Faraji, H., Moghadam, M.G., \& Samadi, A. (2011). Effects of concurrent exercise protocols on strength, aerobic power, flexibility and body composition. Kinesiology, 43(2), 155-162.

Armstrong, N., \& Welsman, J. (1990). Young People and Physical Activity. Oxford: University Press.

Armstrong, N. \& Welsman, J. (2002). Young people and physical activity. Oxford: University Press.

Baquet, G., Berthoin, S., Dupont, G., Blondel, N., Fabre, C., van Praagh, E. (2002). Effects of high intensity intermittent training on peak VO (2) in prepubertal children. International Journal of Sp orts Medicine, 23(6), 439-44. https://doi.org/10.1055/s-2002-33742

Baquet, G., van Praagh, E., \& Berthoin, S. (2003). Endurance training and aerobic fitness in young people. Sports Medicine, 33(15): 1127-1143. https://doi.org/10.2165/00007256-200333150-00004

Benson, A.C., Torode, M.E., \& Singh, M.A.F. (2007). A rationale and method for high-intensity progressive resistance training with children and adolescents. Contemporary Clinical Trials, 28(4), 442-450. https://doi.org/10.1016/i.cct.2006.11.004

Blair, S.N., Kohl, H.W., Paffenbarger, R.S., Clark, D.G., Cooper, K.H.; Gibbons, L.W. (1989). Physical fitness and all-cause mortality. A prospective study of healthy men and women. JAMA, 262(17), 2395-2401. https://doi.org/10.1001/jama.1989.03430170057028

Cadore, E.L., Pinto, R.S., Lhullier, F.L., Correa, C.S., Alberton, C.L., Pinto, S.S., Almeida, A.P., Tartaruga, M.P., Silva, E.M., \& Kruel., L.F. (2010). Physiological effects of concurrent training in elderly men. International Journal of Sports Medicine, 31(10), 689-697. https://doi.org/10.1055/s0030-1261895

Cadore E.L., Pinto, R.S., Pinto, S.S., Alberton, C.L., Correa, C.S., Tartaruga, M.P., Silva, E.M., Almeida, A.P., Trindade, G.T., \& Kruel, L.F. (2011). Effects of strength, endurance, and concurrent training on aerobic power and dynamic neuromuscular economy in elderly men. Journal of Strength \& Conditioning Research, 25(3), 758-766. https://doi.org/10.1519/JSC.0b013e318207ed66

Cadore, E.L., Izquierdo, M., Alberton, C.L., Pinto, R.S., Conceição, M., Cunha, G., Radaelli, R., Bottaro, M, Trindade, G.T, \& Kruel, L.F. (2012). Strength prior to endurance intra-session exercise sequence optimizes neuromuscular and cardiovascular gains in elderly men. Experimental Gerontology, 47(2),164-169. https://doi.org/10.1016/i.exger.2011.11.013

Cadore, E.L., Pinto, R.S., Bottaro, M., \& Izquierdo, M. (2014). Strength and endurance training prescription in healthy and frail elderly. Aging and Disease, 5(3), 183-195. https://doi.org/10.14336/AD.2014.0500183

Carazo-Vargas, P., \& Moncada-Jiménez, J. (2015). A meta-analysis on the effects of exercise training on the VO2max in children and adolescents. Retos, 27, 184-187.

Cepero, M., López, R., Suárez-Llorca, C., Andreu-Cabrera, E., \& Rojas, F.J. (2011). Fitness test profiles in children aged 8-12 years old in Granada (Spain). Journal of Human \& Exercise, 6 (1), 135-145. https://doi.org/10.4100/ihse.2011.61.15

Chtara, M., Chamari, K., Chaouachi, M., Chaouachi, A., Koubaa, D., Feki, Y., Millet, G., \& Amri, M. (2005). Effects of intra-session concurrent endurance and strength training sequence on aerobic performance and capacity. British Journal of Sports Medicine, 39(8), 555-560. https://doi.org/10.1136/bjsm.2004.015248

Chtara, M., Chaouachi, A., Levin, G.T., Chaouachi, M., Chamari, K., Amri, M., \& Laursen, P.B. (2008). Effect of concurrent endurance and circuit resistance training sequence on muscular strength and 
power development. Journal of Strength \& Conditioning Research, 22 (4), 1037-1045. https://doi.org/10.1519/JSC.0b013e31816a4419

Collins, M.A., \& Snow, T.K. (1993) Are adaptations to combined endurance and strength training affected by the sequence of training? Journal of Sports Sciences, 11(6), 485-491. https://doi.org/10.1080/02640419308730017

Dahab, K.S., \& McCambridge, T.M. (2009). Strength training in children and adolescents: Raising the bar for young athletes? Sports Health, 1(3), 223-226. https://doi.org/10.1177/1941738109334215

Davis, W.J., Wood, D.T., Andrews, R.G., Elkind, L.M., \& Davis, W.B. (2008a). Concurrent training enhances athletes' cardiovascular and cardiorespiratory measures. Journal of Strength \&Conditioning Research, 22(5), 1503-1514. https://doi.org/10.1519/JSC.0b013e3181739f9f

Davis, W.J., Wood, D.T., Andrews, R.G., Elkind, L.M., \& Davis, W.B. (2008b) Concurrent training enhances athletes' strength, muscle endurance, and other measures. Journal of Strength \& Conditioning Research, 22(5), 1487-1502. https://doi.org/10.1519/JSC.0b013e3181739f08

Faigenbaum, A.D., Westcott, W.L., Micheli, L.J., Outerbridge, A.R., Long, C.J., LaRosa-Loud, R., \& Zaichkowsky, L. D. (1996). The effects of strength training and detraining on children. Journal of Strength \& Conditioning Research, 10(2), 109-14. https://doi.org/10.1519/15334287(1996)010<0109:TEOSTA>2.3.CO;2

Faigenbaum, A.D., Milliken, L.A., \& Westcott, W.L. (2003). Maximal strength testing in children. Journal of Strength \& Conditioning Research, 17(1), 162-166.

Faigenbaum, A.D., Milliken, L.A., Cloutier, G., \& Westcott, W.L. (2004). Perceived exertion during resistance exercise by children. Perceptual and Motor Skills, 98(2), 627-637. https://doi.org/10.2466/pms.98.2.627-637

Faigenbaum, A.D., \& Westcott, W.L. (2009a). Youth Strength Training: Programs for health, fitness and sport. (2nd ed). USA: Human Kinetics.

Faigenbaum, A.D., Kraemer, W.J., Blimkie, C.J., Jeffreys, I., Micheli, L.J., Nitka, M., \& Rowland, T.W. (2009b). Youth resistance training: Updated position statement paper from the National Strength and Conditioning Association. Journal of Strength \& Conditioning Research, 23(5 Suppl), S60-S79. https://doi.org/10.1519/JSC.0b013e31819df407

Falk, B., \& Tenenbaum, G. (1996). The effectiveness of resistance training in children. A meta-analysis. Sports Medicine, 22(3), 176-186. https://doi.org/10.2165/00007256-199622030-00004

Fyfe, J.J., Bishop, D.J., \& Stepto, N.K. (2014). Interference between concurrent resistance and endurance exercise: Molecular bases and the role of individual training variables. Sports Medicine, 44 (6), 743-762. https://doi.org/10.1007/s40279-014-0162-1

Garber, C.E., Blissmer, B., Deschenes, M.R., Franklin, B.A., Lamonte, M.J., Lee, I.M., Nieman, D.C., \& Swain, D.P. (2011). American College of Sport Medicine position stand. Quantity and quality of exercise for developing and maintaining cardiorespiratory, musculoskeletal, and neuromotor fitness in apparently healthy adults: Guidance for prescribing exercise. Medicine \& Science in Sports \& Exercise, 43(7), 1334-1359. https://doi.org/10.1249/MSS.0b013e318213fefb

García-Pallarés, J., Sánchez-Medina, L., Pérez, C. E., Izquierdo-Gabarren, M. \& Izquierdo, M. (2010). Physiological effects of tapering and detraining in world-class kayakers. Medicine \& Science in Sports \& Exercise, 42 (6), 1209-1214.

García-Pallarés, J., \& Izquierdo, M. (2011). Strategies to optimize concurrent training of strength and aerobic fitness for rowing and canoeing. Sports Medicine, 41(4), 329-343. https://doi.org/10.2165/11539690-000000000-00000

Gergley, J.C. (2009). Comparison of two lower-body modes of endurance training on lower- body strength development while concurrently training. Journal of Strength \& Conditioning Research, 23 (3), 979-987. https://doi.org/10.1519/JSC.0b013e3181a0629d 
Greenleaf, C.A., Petrie, T.A., \& Martin, S.B. (2010). Psychosocial variables associated with body composition and cardiorespiratory fitness in middle school students. Research Quarterly for Exercise \& Sport, 81(3 Suppl), S65-S74. https://doi.org/10.5641/027013610X13100547898239

Häkkinen, K., Alen, M., Kraemer, W.J., Gorostiaga, E., Izquierdo, M., Rusko, H., Mlkkola, J., Hakkinen, A., Valkeinen, H., Kaarakeinen, E., Romu, S., Erola, V., Ahtiainen, K., \& Paavolainen, L. (2003). Neuromuscular adaptations during concurrent strength and endurance training versus strength training. European Journal of Applied Physiology, 89 (1), 42-52. https://doi.org/10.1007/s00421-002$\underline{0751-9}$

Hass, C.J., Feigenbaum, M.S., \& Franklin, B.A. (2001). Prescription of resistance training for healthy populations. Sports Medicine, 31(14), 953-964. https://doi.org/10.2165/00007256-200131140-00001

Hickson, R.C. (1980). Interference of strength development by simultaneously training for strength and endurance. European Journal of Applied Physiology Occupational Physiology, 45(2-3), 255-263. https://doi.org/10.1007/BF00421333

Holviala, J., Häkkinen, A., Karavirta, L., Nyman, K., Izquierdo, M., Gorostiaga, E.M., Avela, J., Korhonen, J., Knuutila, V.P., Kraemer, W.J., \& Häkkinen, K. (2010). Effects of combined strength and endurance training on treadmill load carrying walking performance in aging men. Journal of Strength \& Conditioning Research, 24(6), 1584-1595. https://doi.org/10.1519/JSC.0b013e3181dba178

Izquierdo, M., Häkkinen, K., Ibañez, J., Anton, A., Garrues, M., Ruesta, M., \& Gorostiaga, E.M. (2003). Effects of strength training on submaximal and maximal endurance performance capacity in middleaged and older men. Journal of Strength \& Conditioning Research, 17 (1), 129-139.

Izquierdo, M., Häkkinen, K., Ibañez, J., Kraemer, W.J., \& Gorostiaga, E.M. (2005). Effects of combined resistance and cardiovascular training on strength, power, muscle cross-sectional area, and endurance markers in middle-aged men. European Journal of Applied Physiology, 94(1-2), 70-75. https://doi.org/10.1007/s00421-004-1280-5

Izquierdo-Gabarren, M., Expósito, R.G.T., García-Pallarés, J., Sánchez-Medina, L., De Villarreal, E.S., \& Izquierdo, M. (2010). Concurrent endurance and strength training not to failure optimizes performance gains. Medicine \& Science in Sports \& Exercise, 42(6), 1191-1199.

Kang, J., Rashti, S.L., Tranchina, C.P., Ratamess, N.A., Faigenbaum, A.D. \& Hoffman, J.R. (2009). Effect of preceding resistance exercise on metabolism during subsequent aerobic session. European Journal of Applied Physiology, 107(1), 43-50. https://doi.org/10.1007/s00421-009-1100-z

Kang, Y., \& Ratamess, N. (2014). Which Comes First? Resistance Before Aerobic Exercise or Vice Versa? American College of Sports Medicine, 18(1), 9-14. https://doi.org/10.1249/FIT.0000000000000004

Katch, V.L. (1983). Physical conditioning of children. Journal of Adolescent Health Care, 3(4), 241-246. https://doi.org/10.1016/S0197-0070(83)80245-9

Kelley, D.E., He, J., Menshikova, E.V., \& Ritov, V.B. (2002). Dysfunction of mitochondria in human skeletal muscle in type 2 diabetes. Diabetes, 51(10), 2944-2950. https://doi.org/10.2337/diabetes.51.10.2944

Kobayashi, K., Kitamura, K., Miura, M., Sodeyama, H., Murase, Y., Miyashita, M., \& Matsui, H. (1978). Aerobic power as related to body growth and training in Japanese boys: A longitudinal study. Journal of Applied Physiology, 44(5), 666-672. https://doi.org/10.1152/jappl.1978.44.5.666

Kraemer, W.J., Patton, J.F., Gordon, S.E., Harman, E.A., Deschenes, M.R., Reynolds, K., Newton, R.U., Triplett, N.T, \& Dziados, J. E. (1995). Compatibility of high-intensity strength and endurance training on hormonal and skeletal muscle adaptations. Journal of Applied Physiology, 78(3), 976-989. https://doi.org/10.1152/jappl.1995.78.3.976 
Küüsmaa, M. (2013). Effects of 24 weeks of single session combined strength and endurance training on body compositition and fitness: Examination of order effect. (Unpublished master's thesis, University of Jyväskylä, Finland.

Leveritt M., Abernethy, P.J., Barry, B.K., \& Logan, P.A. (1999). Concurrent strength and endurance training. A review. Sports Medicine, 28(6), 413-427. https://doi.org/10.2165/00007256-19992806000004

Malina, R.M., Beunen, G.P., Classens, A.L., Lefevre, J., Eynde, B.V., Renson, R., Vanreusel, B., \& Simons, J. (1995). Fatness and physical fitness of girls 7 to 17 years. Obesity Research \& Clinical Practice, 3(3), 221-231. https://doi.org/10.1002/j.1550-8528.1995.tb00142.x

Malina, R.M. (2006). Weight training in youth-growth, maturation and safety: An evidenced-based review. Clinical Journal of Sport Medicine, 16(6), 478-487. https://doi.org/10.1097/01.jsm.0000248843.31874.be

Mandigout, S., Lecoq, A.M., Courteix, D., Guenon, P., \& Obert, P. (2001). Effect of gender in response to an aerobic training programme in prepubertal children. Acta Paediatrica, 90 (1): 9-15. https://doi.org/10.1111/j.1651-2227.2001.tb00249.x

Marta, C.C., Marinho, D.A., Barbosa, T.M., Izquierdo, M., \& Marques, M.C. (2013). Effects of concurrent training on explosive strength and VO2max in prepubescent children. International Journal of Sports Medicine, 34 (10), 888-896. https://doi.org/10.1055/s-0033-1333695

Martínez-Vizcaíno, V., \& Sánchez-López, M. (2008). Relationship Between Physical Activity and Physical Fitness in Children and Adolescents. Revista Española de Cardiología, 61(2), 108-111. https://doi.org/10.1157/13116196

Massicotte, D.R. \& Macnab, R.B. (1974). Cardiorespiratory adaptations to training at specified intensities in children. Medicine \& Science in Sports \& Exercise, 6(4), 242-246.

Matos, N., \& Winsley, R.J. (2007). Trainability of young athletes and overtraining. Journal of Sports Science \& Medicine, 6(3), 353-367.

Matton, L., Duvigneaud, N., Wijndaele, K., Philippaerts, R., Duquet, W., Beunen, G., Claessens, A.L., Thomis, M., \& Lefevre, J. (2007). Secular trends in anthropometric characteristics, physical fitness, physical activity and biological maturation in Flemish adolescents between 1969 and 2005. American Journal of Human Biology, 19(3), 345-357. https://doi.org/10.1002/aihb.20592

McCarthy, J.P., Agre, J.C., Graf, B.K., Pozniak, M.A., \& Vailas, A.C. (1995). Compatibility of adaptive responses with combining strength and endurance training. Medicine \& Science in Sports \& Exercise, 27(3), 429-436. https://doi.org/10.1249/00005768-199503000-00021

McCarthy, J.P., Pozniak, M.A. \& Agre, J.C. (2002). Neuromuscular adaptations to concurrent strength and endurance training. Medicine \& Science in Sports \& Exercise, 34 (3), 511-519. https://doi.org/10.1097/00005768-200203000-00019

Micheli, L.J., Glassman, R., \& Klein, M. (2000). The prevention of sports injuries in children. Clinics in Sports Medicine, 19(4),821-834. https://doi.org/10.1016/S0278-5919(05)70239-8

Mirwald, R.L., Bailey, D.A., Cameron, N., \& Rasmussen, R.L. (1981). Longitudinal comparison of aerobic power in active and inactive boys aged 7.0 to 17.0 years. Annals of Human Biology, 8(5), 405-414. https://doi.org/10.1080/03014468100005231

Moreno, J.A., Cervelló, E., \& Moreno, R. (2007). El autoconcepto físico como predictor de la intención de ser físicamente activo. Psicología y Salud,17(2), 261-267.

Ortega, F.B., Tresaco, B., Ruiz, J.R., Moreno, L.A., Martin-Matillas, M., Mesa, J.L., Warnberg, J., Bueno, M., Tercedor, P., Gutiérrez, A., \& Castillo, M.J. (2007). Cardiorespiratory fitness and sedentary activities are associated with adiposity in adolescents. Obesity, 15(6), 1589-1599. https://doi.org/10.1038/oby.2007.188 
Ortega, F.B., Ruiz, J.R., Hurtig-Wennlöf, A., \& Sjöström, M. (2008a). Los adolescentes físicamente activos presentan más probabilidad de una capacidad cardiovascluar saludable independientemente del grado de adiposidad. The European Youth Heart Study. Revista Española de Cardiología, 61(2),123-129. https://doi.org/10.1157/13116199

Ortega, F.B., Ruiz, J.R., Castillo, M.J., \& Sjöström, M. (2008b). Physical fitness in childhood and adolescence: A powerful marker of health. International Journal of Obesity, 32 (1), 1-11. https://doi.org/10.1038/si.jijo.0803774

Ortega, F.B., Silventoinen, K., Tynelius, P., \& Rasmussen, F. (2012). Muscular strength in male adolescents and premature death: Cohort study of one million participants. British Medical Journal, 20, 345, e7279. https://doi.org/10.1136/bmj.e7279

Ozmun, J.C., Mikesky, A.E., \& Surburg, P.R. (1994). Neuromuscular adaptations following prepubescent strength training. Medicine \& Science in Sports \& Exercise, 26(4), 510-514. https://doi.org/10.1249/00005768-199404000-00017

Pate, R.R., Ward, D.S. (1990). Endurance exercise trainability in children and youth. Chicago: Year Book Publishers, 37-55.

Payne, V.G., Morrow, J.R., Johnson, L., \& Dalton, S.N. (1997). Resistance training in children and youth: A meta-analysis. Research Quarterly for Exercise \& Sport, 68(1), 80-88. https://doi.org/10.1080/02701367.1997.10608869

Pfeiffer, K. A., Lobelo, F., Ward, D. S., \& Pate, R. R. (2008). Endurance trainability of children and youth: The Young Athlete. Oxford: Blackwell, 84-95.

Pijnappels, M., van der Burg, P.J., Reeves, N.D., \& van Dieën, J.H. (2008). Identification of elderly fallers by muscle strength measures. European Journal of Applied Physiology, 102(5), 585-592. https://doi.org/10.1007/s00421-007-0613-6

Pitukcheewanont, P., Punyasavatsut, N., \& Feuille, M. (2010). Physical activity and bone health in children and adolescents. Pediatric Endocrinology Reviews, 7(3), 275-282.

Rahnama, N., Gaeini, A.A., \& Hamedinia, M.R. (2007). Oxidative stress responses in physical education students during 8 weeks aerobic training. Journal of Sports Medicine and Physical Fitness, 47, 119123.

Ramsay, J.A., Blimkie, C.J., Smith, K., Garner, S., MacDougall, J.D, \& Sale, D.G. (1990). Strength training effects in prepubescent boys. Medicine \& Science in Sports \& Exercise, 22(5), 605-614. https://doi.org/10.1249/00005768-199010000-00011

Roetert, E.P. (2004). The lack of childhood activity in the United States. Strength \& Conditioning Journal, 26(2), 22-23. https://doi.org/10.1519/00126548-200404000-00003

Ruiz, J.R., Castro- Piñero, J., Artero, E.G., Ortega, F.B., Sjöström, M., Suni, J., \& Castillo, M. J. (2009). Predictive validity of health-related fitness in youth: A systematic review. British Journal of Sports Medicine, 43(12), 909-923. https://doi.org/10.1136/bjsm.2008.056499

Sadres, E., Eliakim, A., Constantini, N., Lidor, R., \& Falk, B. (2001). The effect of long-term resistance training on anthropometric measures, muscle strength, and self-concept in pre-pubertal boys. Pediatric Exercise Science, 13(4), 357-372. https://doi.org/10.1123/pes.13.4.357

Sale, D.G., McDougall, J.D., Jacobs, I., \& Garner, S. (1990). Interaction between concurrent strength and endurance training. Journal of Applied Physiology, 68(1), 260-270. https://doi.org/10.1152/jappl.1990.68.1.260

Santos, A., Marinho, D.A., Costa, A.M., Izquierdo, M., \& Marques, M.C. (2011). Effects of a concurrent strength and endurance training/detraining program follow a specific detraining cycle on strength and aerobic fitness in school girls. Journal of Human Kinetics, 29A, 93-103. https://doi.org/10.2478/v10078-011-0064-3 
Santos, A., Marinho, D.A., Costa, A.M., Izquierdo, M., \& Marques, M.C. (2012). The effects of concurrent resistance and endurance training follow a detraining period in elementary school students. Journal of Strength \& Conditioning Research, $26 \quad$ (6), 1708-1716. https://doi.org/10.1519/JSC.0b013e318234e872

Santos, R., Mota, J., Santos, D.A., Silva, A.M., Baptista, F., \& Sardinha, L.B. (2014). Physical fitness percentiles for Portuguese children and adolescents aged 10-18 years. Journal of Sports Sciences, 32(16), 1510-1518. https://doi.org/10.1080/02640414.2014.906046

Shaw, B.S., Shaw, I., \& Brown, G.A. (2009). Comparison of resistance and concurrent resistance and endurance training regimes in the development of strength. Journal of Strength \& Conditioning Research, 23(9), 2507-2514. https://doi.org/10.1519/JSC.0b013e3181bc191e

Shephard, R.J. (1992). Effectiveness of training programmes for prepubescent children. Sports Medicine, 13 (3), 194-213. https://doi.org/10.2165/00007256-199213030-00004

Sillanpää, E., Häkkinen, A., Nyman, K., Mattila, M., Cheng, S., Karavirta, L., Laaksonen, D.E., Huuhka, N., Kraemer, W.J., \& Häkkinen, K. (2008). Body composition and fitness during strength and/or endurance training in older men. Medicine \& Science in Sports Exercise, 40 (5), 950-958. https://doi.org/10.1249/MSS.0b013e318165c854

Silva, R.F., Cadore, E.L., Kothe, G., Guedes, M., Alberton, C.L., Pinto, S.S., Trindade, G., \& Kruel, L.F. (2012). Concurrent training with different aerobic exercises. International Journal of Sports Medicine, 33(8), 627-634. https://doi.org/10.1055/s-0031-1299698

South African Sports Medicine Association. (2008). Resistance training in children and adolescents. South African Sports Medicine Association (SASMA) Web site. Accessed October 5, 2016. Available at: http://www.sasma.org.za/?p=132

Steele, R.M., Brage, S., Corder, K., Wareham, N.J., \& Ekelund, U. (2008). Physical activity, cardiorespiratory fitness, and the metabolic syndrome in youth. Journal of Applied Physiology, 105(1), 342-351. https://doi.org/10.1152/japplphysiol.00072.2008

Steinberger, J. (2003). Diagnosis of the metabolic syndrome in children. Current Opinion in Lipidology, 14(6): 555-559. https://doi.org/10.1097/00041433-200312000-00002

Sung, R., Yu, C., Chang, S., Mo, S., Woo, K., \& Lam, C. (2002). Effects of dietary intervention and strength training on blood lipid level in obese children. Archives of Disease in Childhood, 86(6), 407 410. https://doi.org/10.1136/adc.86.6.407

Szymanski, D.J., Szymanski, J.M., Bradford, T.J., Schade, R.L., \& Pascoe, D.D. (2007). Effect of twelve weeks of medicine ball training on high school baseball players. Journal of Strength \& Conditioning Research, 21(3), 894-901.

Takeshima, N., Rogers, N.L., Rogers, M.E., Islam, M.M., Koizumi, D., \& Lee, S. (2007). Functional fitness gain varies in older adults depending on exercise mode. Medicine \& Science in Sports \& Exercise, 39(11), 2036-2043. https://doi.org/10.1249/mss.0b013e31814844b7

Tambalis, K.D., Panagiotakos, D.B., Arnaoutis, G., \& Sidossis, L.S. (2013). Endurance, explosive power and muscle strength in relation to body mass index and physical fitness in Greek children aged 7-10 years. Pediatric Exercise Science, 25(3), 394-406. https://doi.org/10.1123/pes.25.3.394

Tomkinson, G.R., \& Olds, T.S. (2007). Secular changes in pediatric aerobic fitness test performance: The global picture. Medicine and Sport Science, 50, 46-66. https://doi.org/10.1159/000101075

Trost, S.G., Pate, R.R., Sallis, J.F., Freedson, P.S., Taylor, W.C., Dowda, M., \& Sirard, J. (2002). Age and gender differences in objectively measured physical activity in youth. Medicine \& Science in Sports \& Exercise, 34(2), 350-355. https://doi.org/10.1097/00005768-200202000-00025

Tsolakis, C.K., Vagenas, G.K., \& Dessypris, A.G. (2004). Strength adaptations and hormonal responses to resistance training and detraining in preadolescent males. Journal of Strength \& Conditioning Research, 18(3), 625-629. 
Vaughn, J.M., \& Micheli, L. (2008). Strength training recommendations for the young athlete. Physical Medicine \& Rehabilitation Clinics of North America, 19(2), 235-245. https://doi.org/10.1016/i.pmr.2007.11.004

Wijndaele, K., Duvigneaud, N., Matton, L., Duquet, W., Thomis, M., Beunen, G., Lefevre, J., \& Philipphaerts, R.M. (2007). Muscular strength, aerobic fitness, and metabolic syndrome risk in Flemish adults. Medicine \& Science in Sports \& Exercise, 39(2), 233-240. https://doi.org/10.1249/01.mss.0000247003.32589.a6

Wilson, J.M., Marin, P.J., Rhea, M.R., Wilson, S.M., Loenneke, J.P., \& Andersen, J.C. (2012). Concurrent training: a meta-analysis examining interference of aerobic and resistance exercises. Journal of

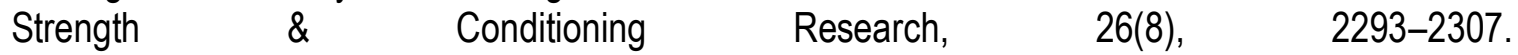
https://doi.org/10.1519/JSC.0b013e31823a3e2d

Yu, C.C., Sung, R.Y., Hau, K.T., Lam, P.K., Nelson, E.A., \& So, R.C. (2008). The effect of diet and strength training on obese children's physical self-concept. The Journal of Sports Medicine and Physical Fitness, 48(1), 76-82. 